allow of the poison being worked off in small non-lethal doses. It seems to me that if the circulation be brought to a standstill at the seat of injeotion it might be possible, if this be done early enough, to prevent any venom at all entering. The venom would be imprisoned, as it were, and could be dealt with by permanganate of potash and incisions. I suggest, therefore, that in cases seen early enough the part be frozen with ethyl chloride spray during the making of the incisions and the rubbing in of permanganate of potash. Where the subcutaneous cellular tissue is loose the part containing the imprisoned poison might be shut off from the general circulation by ligature should needles and thread be handy. All the operations would be painless. A tube of ethyl chloride would not be a large addition to a snake-bite outfit.

Knysna, Cape Colony.

\section{A CASE OF POISONING BY COAL-GAS.} BY JOHN REID, M.D. ABERD.

THE patient in the present case was a female child, born on Feb. 20th. When 1 saw her and her mother on that day I called attention to a slight escape of gas from a bracket in the centre of the room. This bracket was not in use but was tied to the ceiling. On the 21st neither the mother nor the child seemed to suffer from the escaping gas. The room was large and a good fire was burning. On March 8th the child could not suck and had the usual signs of capillary bronchitis. She was in the kitchen, which was somewhat draughty. On the 9th she was removed to the room in which she was born but which had been out of use for a day or two. The change took place after my midday visit, at which $I$ found that marked improvement had occurred in her lung symptoms and that she was able to suck. On the 10th I found very few râles on auscultation, but her lips were chocolate coloured and she was rolling her tongue in the mouth as if gasping for breath. She offered no resistance to examining her throat or to depressing the tongue; on the contrary, there was marked apathy. The eyelids were puffed and a thick mucus exuded from the edges of the swollen lids. The conjunctiva was red on the 8 th and was so on this date, but the cornea had the dull lustre found in interstitial keratitis. The pupil was small; the general aspect of the face was ashy; the mouth was dry; and on the tongue there was thick mucus, but no saliva. The mucus seemed to be pushed out of the mouth by the rolling movements of the tongue and to reaccumulate. There was cyanosis of the soft palate, which was of the same colour as the lips. The abdomen was tympanitic and when it was pressed the child showed some signs of uneasiness. She was constipated but the bowels had been well opened on the 9th. She was placed suitably for fresh air and was fed by milk given with a spoon. On the 11th the skin of the body had a dusky or ashy bue. The bowels had been moved by a piece of soap in the rectum and the tympanic appearance had subsided. The eyelids were now open and there was no mucus on the lids-probably a boric acid lotion had removed it-but the cornea and conjunctiva were injected and the dull look suggesting keratitis was still present. The lips were chocolate coloured and the soft palate was cyanosed. There was a slight improvement in the movements of the tongue, but there still was thick mucus in the mouth. The child took milk readily from a spoon. On the 12th there was a bright roseolar rash over the whole body, including the head. A few sudamina were present, but there were large rosy red patches over great parts of the surface. A magnifying glass showed that the condition was a dermatitis or bleeding under the skin rather than a proper eruption. The colour was bright red. The tongue was now bright red, intolerant of touch, and covered with aphthæ. It was difficult to feed the child but she took milk which was given to her. The chocolate colour of the lips and the cyanosis of the soft palate were now less marked. The condition of the cornea was unchanged. The lungs gave no signs of disease, but only of dryness of the tubes. The motions were black (melæna).

The child's state on March 13th was about the same as on the 12th but the soft palate and lips were now red and showed no chocolate colour. On the 14th her state in the morning was much the same as on the 13th, but towards the evening the rash and aphthæ had pretty well disappeared. She took milk which was given her. The injection of the cornea had passed off but the dull lustreless appearance remained. There were frequent fits of difficult breathing with cyanosis during the day. On the 15th the child looked almost moribund in the morning, but improved with the inhalation described subsequently. There were frequent fits with chocolate colouring of the lips and palate. From the 12th to the 14th there was occasional yawning. It should be mentioned that these fits were not like those met with in fevers and lung affections. There was a semi-comatose state with a chocolate colouring of the lips, which passed off after a time, especially on rousing. In the evening the cornea became more natural and the child's general appearance improved. After the rash had disappeared, in the morning a few bright red patches made their appearance on the fingers; these alone were seen. Her general appearance was more natural, her bowels acted, and the motions were now natural. She was spoon-fed with mother's milk. On the 16 th in the morning she had a convulsive seizure, a general convulsion of an epileptic nature, with foaming at the mouth but with little cyanosis. She had been fed during the night and the milk had been returned curdled. Jelly and trypsinised milk were now substituted and retained. At 6 P.M. the child looked natural; she had had no fits but her heart's action was weak. She died from syncope at 7.50 P.M. Marked hypostatic lividity was observed 16 hours after death and a roseolar raised eruption, of a dull character, was at the same time present over the body but not on the head; it was, however, much less copious than during life.

The mother's milk, which ceased on the 10th, was brought back on the 12th by pilocarpine, and on the 16th she had lost all the cyanotic signs from her lips. Evidently the first symptoms of carbon monoxide poisoning were paralysis of the salivary, lacteal, and lacrymal glands, with headache in the case of the mother, and stimulation of mucous glands, or glands of organic life. The fit which the child had on the morning of the 16th was, I think, owing to enfeebled circulation and was not of the carbon monoxide type. The milk had been returned from the stomach curdled.

The treatment up to March 14th consisted of fresh air, appropriate diet, and calomel to move the bowels, and boric acid lotion to bathe the eyes and tongue, with medicines likely to improve secretion. On the $14 \mathrm{th}$, inhalation of chlorine was commenced, the process employed being to mix 10 grains of potassium chlorate with 30 minims of dilute hydrochloric acid in a teacup which was placed near the child's nose until evident signs of irritation occurred. This was frequently repeated during the day. Two minims of this were also added to a two-ounce mixture, of which one-sixteenth part was taken every three hours. It will be observed that the remedy was used late in the case of a very young child, and that no steps were taken to minimise the effects of the release of considerable quantities of carbon dioxide by the chlorine, which formed carbon oxychloride. Probably a more leisurely action employed at an earlier stage would be a safer remedy unless oxygen were available for inhalation, as it was not in this case. I should state that I first used dilute phosphoric acid and potassium chlorate in the mixture, but I think that little or no chlorine resulted from this. The mother recovered rapialy under the treatment. It is rather strange that a dusky or earthy colour at first covered the body. This, I think, was hæmorrhage or pigment of a punctate character. The bright red colour (rash) did not appear till the third day.

Although the antidote was used in the case of a very young subject, debilitated by broncho-pneumonia and tonsillitis (influenza), I feel confident that early and judicious treatment by the chlorine antidote would have led to recovery. As it was death resulted from syncope. It is noteworthy that the mother and child managed to live during the puerperium in the room with a leakage of gas which was repaired on March 11th. The gas became ignited and continued to burn when a lighted match was placed at the point of leakage. The accumulation of gas through the disuse of the room during two days was sufficient to produce very evident signs of poisoning. The child slept in a perambulator, with a hood, both in the kitchen and bedroom. The nursing was good. An inquest was held and the jury returned a verdict in accordance with my evidence.

Walbrook, E.C. 